\title{
Aquisição lexical no desenvolvimento normal e alterado de linguagem - um estudo experimental
}

\author{
Juliana Perina Gândara ${ }^{1}$
}

Gândara JP. Aquisição lexical no desenvolvimento normal e alterado de linguagem - um estudo experimental [tese de doutorado]. São Paulo: Faculdade de Filosofia, Letras e Ciências Humanas, Universidade de São Paulo; 2008.

A aquisição lexical é uma das primeiras manifestações observáveis no desenvolvimento normal da linguagem, e, portanto, alterações nesse processo constituem um marco inicial das Alterações no Desenvolvimento da Linguagem (AEDL). O objetivo principal deste trabalho foi investigar a aquisição lexical de crianças normais e aquelas com AEDL, em três situações de apresentação de novas palavras, que reproduziam contextos freqüentemente usados na intervenção fonoaudiológica. Vinte e uma crianças com AEDL (GP) e 30 em desenvolvimento normal (GC), todas na faixa etária de três anos, foram randomicamente designadas a um dos subgrupos de exposição: G1 - brincadeira simbólica, G2 - jogo, G3 - interação baseada em livro de história. As mesmas cinco não-palavras foram apresentadas em quantidade controlada aos sujeitos de cada subgrupo, em três sessões de interação, na presença dos respectivos referentes, também desconhecidos. O desempenho dos sujeitos foi analisado, considerando a situação natural de interação (Etapa I) e tarefas de nomeação, compreensão e reconhecimento das novas palavras em um pós-teste realizado a cada sessão (Etapa II). Para melhor discussão dos dados, a pesquisa foi dividida em três estudos. O Estudo 1 analisou o desempenho do GC no procedimento experimental e mostrou algumas diferenças do GC3 em relação aos outros subgrupos de exposição, nas medidas referentes à Etapa I, refletindo que a presença física dos referentes, a demanda atencional e o nível de maturidade simbólica, necessários para a aquisição podem ter influenciado as respostas dos sujeitos desse subgrupo. Os sujeitos do GC, de maneira geral, apresentaram melhores habilidades de compreensão que de nomeação, e evoluíram ao longo das sessões em relação às variáveis que indicaram aquisição (produção espontânea na Etapa I; compreensão e nomeação na Etapa II). O Estudo 2 analisou o desempenho do GP no procedimento experimental, contrastando os resultados com os apresentados pelo GC, e mostrou que os processos envolvidos e a influência das variáveis analisadas foram os mesmos para os dois grupos. As diferenças entre eles foram quantitativas e qualitativas, sugerindo que as crianças com AEDL necessitam de maior quantidade de experiências e demoram mais tempo do que seus pares em desenvolvimento normal para adquirirem uma nova palavra. Tanto no GC quanto no GP, a imitação não-solicitada foi utilizada por alguns sujeitos como estratégia para a aquisição das palavras, mostrando correlação positiva com a ocorrência de produções espontâneas. O Estudo 3 correlacionou as habilidades demonstradas pelos sujeitos dos dois grupos em adquirir palavras e o domínio lexical medido em prova específica de vocabulário expressivo. A correlação positiva entre essas habilidades, nos dois grupos, e ainda com a quantidade de intervenção fonoaudiológica anterior recebida pelos sujeitos do GP sugeriram que a prática em adquirir palavras influenciou positivamente o desempenho na tarefa de aquisição dos novos itens lexicais. Considerados em conjunto, os resultados mostraram grande variabilidade de desempenho em ambos os grupos, indicando que a aquisição lexical é um processo individual e heterogêneo, e que as habilidades de cada criança com AEDL devem ser consideradas individualmente no processo terapêutico para que este seja o mais efetivo possível.

Tese apresentada ao Programa de Pós-graduação em Semiótica e Lingüística Geral da Faculdade de Filosofia, Letras e Ciências Humanas da Universidade de São Paulo - USP - São Paulo (SP), Brasil, realizada sob orientação da Profa. Dra. Debora Maria Befi-Lopes.

(1) Doutora; Colaboradora do Laboratório de Investigação Fonoaudiológica em Desenvolvimento da Linguagem e suas Alterações do Departamento de Fisioterapia, Fonoaudiologia e Terapia Ocupacional da Faculdade de Medicina da Universidade de São Paulo - USP - São Paulo (SP), Brasil.

Endereço para correspondência: Juliana Perina Gândara. R. Cipotânea, 51, Cidade Universitária, São Paulo - SP, CEP 05360-160.

E-mail: jpgandara@usp.br 